\title{
Controlling Rhizoctonia Damping-off of Chinese Mustard by Using Endomycorrhizal Rhizoctonia spp. Isolated from Orchid Mycorrhizae
}

Jr-Hau Jiang and Si-Loi Tam, Department of Plant Pathology, National Chung Hsing University, Taichung, Taiwan; Takeshi Toda, Faculty of Bioresource Science, Akita Prefectural University, Shimo-shinjo, Akita 010-0195, Japan; and Lung-Chung Chen, Department of Plant Pathology, National Chung Hsing University, Taichung, Taiwan

\begin{abstract}
Jiang, J.-H., Tam, S.-L., Toda, T., and Chen, L.-C. 2016. Controlling Rhizoctonia damping-off of Chinese mustard by using endomycorrhizal Rhizoctonia spp. isolated from orchid mycorrhizae. Plant Dis. 100:85-91.

Inoculation of hypovirulent Rhizoctonia spp. has been recognized as an effective strategy for protecting plants against damping-off caused by pathogenic Rhizoctonia spp. In this study, endomycorrhizal Rhizoctonia spp. isolated from fungal pelotons in orchid plants were used for controlling Rhizoctonia damping-off of Chinese mustard. According to phylogenetic analysis and anastomosis group (AG) determination, the virulence of three isolates of multinucleate Rhizoctonia solani in AG-6; eight isolates of binucleate Rhizoctonia in AG-A, AG-B, AG-G, AG-P, and AG-R; and two isolates of binucleate $R$. repens were evaluated using test plants. All

isolates, except that in AG-R, caused low disease severity in 10-day-old radish (0.10 to 0.61), cucumber (0.28 to 0.54$)$, and Chinese mustard (0.18 to 0.65). By contrast, pathogenic isolates in AG-4 killed almost all test plants with symptoms of collapsed hypocotyl and wilted leaves (0.88 to 0.96). Of the 13 endomycorrhizal Rhizoctonia isolates assessed, AG-P isolates Cno10-3 and CalS1-2 provided 91 and 100\% protection, respectively, against $R$. solani AG-4 in 26-day-old Chinese mustard. This study revealed that endomycorrhizal Rhizoctonia spp. in orchid have the potential to biologically control damping-off of Chinese mustard.
\end{abstract}

Orchidaceae is one of the largest and most diverse plant families, including an estimated 20,000 to 35,000 species in the plant kingdom (12). Several researchers have confirmed that the primary mycorrhizal fungi associated with green orchid are Ceratobasidiaceae, Tulasnellaceae, and Sebacinaceae fungi $(13,38)$; these fungi can be recognized as the form genus Rhizoctonia $(33,40,49)$. Genus Rhizoctonia was first described by De Candolle (1815) and is considered a heterogeneous assemblage of filamentous fungal taxa (16). Although many reports have listed various saprophytic and symbiotic taxa, the organisms belonging to this genus are typically pathogens, which are primarily associated with host roots (39). Pathogenic Rhizoctonia solani Kühn often severely damages crops, ornamental plants, and trees (16).

Genus Rhizoctonia comprises multinucleate Rhizoctonia spp. (MNR), binucleate Rhizoctonia spp. (BNR), and uninucleate Rhizoctonia spp. (36). Most MNR and BNR are further divided into various anastomosis groups (AGs). At present, the multinucleate $R$. solani (teleomorph $=$ Thanatephorus cucumeris (A. B. Frank) Donk) contains 14 AGs (AG-1 to AG-13 and AG-BI) $(9,16)$, whereas BNR (teleomorph $=$ Ceratobasidium D. P. Rogers) are divided into at least 16 AGs (AG-A to AG-I, AG-K, AG-L, and AG-O to AG-S) (36). Within the same AG, isolates may exhibit similar characteristics, such as types of disease symptoms caused and host preferences (21). Moreover, several studies have demonstrated that some BNR (e.g., isolates in AG-B $(\mathrm{O}), \mathrm{AG}-\mathrm{G}$, and $\mathrm{AG}-\mathrm{P}$ ) are hypovirulent to crops and can provide protection from damping-off $(19,39)$. Alternative methods of control such as using biocontrol organisms have been considerably investigated since soil fumigation was prohibited (35).

Various hypovirulent BNR isolated from soil have been confirmed to act against pathogenic Rhizoctonia spp., and certain isolates have yielded 75 to $95 \%$ protection $(41)$. In soybean $(22,32)$, bean $(18,50)$,

Corresponding author: L.-C. Chen; E-mail: 1cchen5a08@ gmail.com

*The $\boldsymbol{e}$-Xtra logo stands for "electronic extra" and indicates that one supplementary figure is published online.

Accepted for publication 26 April 2015.

http://dx.doi.org/10.1094/PDIS-06-14-0597-RE

(C) 2016 The American Phytopathological Society cucumber (20), cotton (19), tomato (26), and spinach (27), certain isolates of hypovirulent BNR have been shown to act as inducing agents, leading to systemic resistance against pathogenic fungi such as $R$. solani, Fusarium oxysporum f. sp. radicis-lycopersici, and $F$. oxysporum f. sp. spinaciae. Recently, isolates of Ceratobasidium from orchid have been used to suppress rice sheath blight disease caused by $R$. solani AG-1 IA (25). Moreover, certain MNR and BNR species are mycorrhizal symbionts of orchid, whose minute seed pass through a nonphotosynthetic phase in which they depend on an external supply of nutrients and require an association with a compatible fungus to obtain sufficient nutrition for germination (3). According to the classification of AG determination, certain isolates in three AGs of MNR (AG-5, AG-6, and AG-12) and four AGs of BNR (AG-A, AG-C, AG-E, and AG-I) have been reported to form orchid mycorrhizae with wild orchid $(10,31,40,47)$. Mosquera-Espinosa et al. (25) indicated that isolates of BNR (teleomorph = Ceratobasidium) that originated from an association with terrestrial orchid are more likely to survive in soil environments and provide effective biological control compared with Rhizoctonia fungi isolated from epiphytic orchid species adapted to live on tree bark.

No studies have involved using endomycorrhizal Rhizoctonia fungi to control vegetable damping-off caused by pathogenic $R$. solani AG-4, a major pathogen on a wide variety of hosts (e.g., radish, cauliflower, cabbage, carrot, and cucumber) (46). The damping-off caused by $R$. solani AG-4 is particularly severe in plug trays if the surviving inoculum touches emerging seedlings of Chinese mustard (Brassica rapa var. chinensis). Isolates of endomycorrhizal Rhizoctonia spp. in our study were obtained from fungal pelotons in the roots or rhizomes of wild orchid. Little is known regarding the pathogenicity, virulence, and mycorrhizal symbiosis of orchid mycorrhizal fungi, particularly endomycorrhizal Rhizoctonia spp. Thus, the objectives of this study were to (i) identify isolates of endomycorrhizal Rhizoctonia sampled from fungal pelotons in wild orchid in Taiwan according to morphology, AG determination, and phylogenetic analysis of the internal transcribed spacer (ITS) region with 5.8S ribosomal DNA (rDNA-ITS); (ii) analyze the virulence of endomycorrhizal Rhizoctonia isolates on radish, cucumber, and Chinese mustard; and (iii) determine which endomycorrhizal Rhizoctonia isolates can control vegetable damping-off caused by $R$. solani AG-4.

\section{Materials and Methods}

Endomycorrhizal Rhizoctonia spp. Sections of the root cortices of wild orchid exhibiting fungal pelotons were excised, surface 
sterilized in a $1 \%$ sodium hypochlorite solution for $1 \mathrm{~min}$, rinsed in sterile water, and transferred to tap water agar (TWA) and potato dextrose agar (PDA) acidified with $0.2 \%$ lactic acid to inhibit the growth of bacteria. After incubation for $48 \mathrm{~h}$ at $24^{\circ} \mathrm{C}$, hyphal tips of Rhizoctonia spp. were selected according to the genus Rhizoctonia; branching and constriction were apparent near the distal septum of cells in young vegetative hyphae; and conidia, clamp connections and rhizomorphs, and sclerotia without differentiating into the rind and medulla were absent (40).

Nuclear number and AGs. Thirteen representative isolates of endomycorrhizal Rhizoctonia from orchid mycorrhizae were initially identified as MNR or BNR after staining with $0.1 \%$ trypan blue in lactophenol (6) or $3 \% \mathrm{KOH}$ and safranin $\mathrm{O}$ (4) and observing the hyphal growth after 4 to 7 days of incubation in PDA at $25^{\circ} \mathrm{C}$. To determine the AGs of endomycorrhizal Rhizoctonia spp., an endomycorrhizal Rhizoctonia isolate of unknown AG and a representative tester strain of known AG were grown on PDA for 2 to 3 days. The mycelial plugs obtained from the advancing margins of pure cultures of each isolate were paired with tester strains in TWA and left to grow at $25^{\circ} \mathrm{C}$. The overlapping portions of hyphae were transferred to a slide, stained with $0.1 \%$ trypan blue in lactophenol, and evaluated for hyphal fusion (9). Three petri dishes were used for each treatment, and experiments were repeated twice. The anastomosis reactions were grouped into four categories ( $\mathrm{C} 0$ to $\mathrm{C} 3$ ) according to the description by Carling (8).

Virulence determination. Radish (Raphanus sativus L.) and cucumber (Cucumis sativus L.) were used as the test crops because Juan-Abgona et al. (20) screened hypovirulent Rhizoctonia spp. by using these crops. The seed were disinfected with $70 \%$ ethanol for $1 \mathrm{~min}$, soaked in $2 \%$ sodium hypochlorite for $5 \mathrm{~min}$, then rinsed three times with sterile distilled water. The seed were pregerminated for 2 days at $25^{\circ} \mathrm{C}$, and five seedlings were transferred to $2 \%$ TWA. Subsequently, a 9-mm mycelial disc obtained from the margin on a 5-day-old mycelium of an endomycorrhizal Rhizoctonia isolate was centered on the TWA and maintained in a growth chamber (16-h photoperiod and daytime illuminance of approximately 10,000 lux) at $25^{\circ} \mathrm{C}$. Two pathogenic isolates from the seedlings of cabbage (B. oleracea var. capitata) and Chinese cabbage (B. rapa var. pekinensis) that caused damping-off were identified as Rhizoctonia solani AG-4 and used as a positive control. Five replicates of each treatment were maintained for 8 days (9) and the experiment was repeated twice. Experiments to determine virulence on radish, cucumber, and Chinese mustard were performed according to a completely randomized design.

For 10-day-old seedlings of radish and Chinese mustard (9), disease severity was determined using the following 5-point scale: $0=$ healthy, exhibiting no lesions on the hypocotyl; $1=$ minor discoloration of the hypocotyl; $2=$ discoloration plus small necrotic lesions $(<1 \mathrm{~mm})$ on the hypocotyl or primary root; $3=$ discoloration plus large necrotic lesions $(>1 \mathrm{~mm}$ ) on the hypocotyl or primary root; and $4=$ collapsed hypocotyl exhibiting wilted leaves or dead seedlings. For cucumber, a modified rating was required to assess disease severity (20), in which $0=$ no lesions on the hypocotyl, $1=$ one or two yellow-brown lesions $(<0.25 \mathrm{~mm}), 2$ = yellow-brown lesions $(<0.5 \mathrm{~mm})$ or water-soaked areas covering $<10 \%$ of the hypocotyl, $3=$ yellow-brown to dark brown lesions $(>0.5 \mathrm{~mm})$ that coalesce with other lesions, or watersoaked areas covering $>10 \%$ of the hypocotyl, and $4=$ collapsed hypocotyl exhibiting wilted leaves or dead seedlings.

Evaluation of plant protection treatments. Inoculum was prepared by growing each isolate of endomycorrhizal and pathogenic Rhizoctonia on PDA for 3 days and transferring three mycelial discs to $200 \mathrm{~g}$ of autoclaved barley grain (1:1 dry barley grain/distilled water [wt/vol]) in 500-ml Erlenmeyer flasks. The cultures were incubated at $25^{\circ} \mathrm{C}$ for 10 days and shaken every 2 days to ensure a uniform distribution of inoculum. Chinese mustard was planted in eight-cell plug trays, with one 10-day-old seedling in each cell, and one barley grain colonized with an isolate of endomycorrhizal Rhizoctonia was placed in each cell. The seedlings were regularly watered and incubated in a growth room at $25^{\circ} \mathrm{C}$ with a 16 -h photoperiod of visible light. Six days after planting, each seedling was challenged with one barley grain that was colonized with the virulent $R$. solani AG-4 isolate Cabl 2 or Chcab4; the grains were placed at an equal distance $(2 \mathrm{~cm})$ from each seedling, except for the noninoculated control. The number of surviving plants was recorded after another 10 days of culturing and the percentage of plant protection was calculated as follows (41): Protection $(\%)=[(\mathrm{A}-\mathrm{B}) /(\mathrm{C}-\mathrm{B})] \times 100$, where $\mathrm{A}$ is the percentage of surviving

Table 1. Isolates of endomycorrhizal Rhizoctonia from fungal pelotons in wild orchid ${ }^{z}$

\begin{tabular}{|c|c|c|c|}
\hline Isolate/accession number & Orchid habitat, locality & Highest Blast hit ${ }^{a}$ & Similarity $(\%)$ \\
\hline \multirow[t]{2}{*}{ ANOF0/KJ495962 } & Anoectochilus formosanus & AF354102, isolate 70Rs & 97 \\
\hline & Terrestrial, Yangmingshan & T. cucumeris strain AG6-HG-I & $\ldots$ \\
\hline \multirow[t]{2}{*}{ ANOF4/KJ495966 } & Anoectochilus formosanus & AF354102, isolate 70Rs & 97 \\
\hline & Terrestrial, Hsinchu & T. cucumeris strain AG6-HG-I & $\ldots$ \\
\hline \multirow[t]{2}{*}{ ANOFD1/KJ495967 } & Anoectochilus formosanus & $\mathrm{AF} 354104$, isolate $75 \mathrm{Rs}$ & 97 \\
\hline & Terrestrial, Wufong & T. cucumeris strain AG6-GV & $\ldots$ \\
\hline \multirow[t]{2}{*}{ Cno3-2/JX514374 } & Zeuxine sp. & AY927362, isolate R78 & 98 \\
\hline & Terrestrial, Wulai, Sansia & Ceratobasidium sp. AG-A & $\ldots$ \\
\hline \multirow[t]{2}{*}{ Sno5-12/JX514386 } & Cleisostoma paniculatum & JQ859885/isolate WUF-ST-RhT4-3 & 93 \\
\hline & epiphytic, Wulai, Sansia & Ceratobasidium sp. AG-B & $\ldots$ \\
\hline \multirow[t]{2}{*}{ Eno3-3/JX514377 } & Goodyera procera & AY927348, isolate R56 & 92 \\
\hline & Terrestrial, Wulai, Sansia & Ceratobasidiumsp. AG-G & $\ldots$ \\
\hline \multirow[t]{2}{*}{ ZeuS1-1/KJ573103 } & Zeuxine strateumatica & DQ102402, isolate Str14 & 99 \\
\hline & Terrestrial, Tainan & Ceratobasidium sp. AG-G & $\ldots$ \\
\hline \multirow[t]{2}{*}{ ANOF2/KJ495964 } & Anoectochilus formosanus & DQ102402, isolate Str14 & 99 \\
\hline & Terrestrial, Nantou & Ceratobasidium sp. AG-G & $\ldots$ \\
\hline \multirow[t]{2}{*}{ Cno10-3/JX514376 } & Cheirostylis hungyehensis & AB286938, isolate: $\mathrm{C}-584$ & 100 \\
\hline & Terrestrial, Wulai, Sansia & Ceratobasidium sp. AG-P & $\ldots$ \\
\hline \multirow[t]{2}{*}{ CalS1-2/JX514384 } & Calanthe sylvatica & AB286941, isolate: C-578 & 95 \\
\hline & Terrestrial, Wulai, Sansia & Ceratobasidium sp. AG-P & $\ldots$ \\
\hline \multirow[t]{2}{*}{ ANOF3/KJ495965 } & Anoectochilus formosanus & AB286942, isolate: $X 4-3$ & 99 \\
\hline & Terrestrial, Wulai, Sansia & Ceratobasidium sp. AG-R & $\ldots$ \\
\hline \multirow[t]{2}{*}{ Sno3-3/JX514385 } & Liparis nakaharai & GU166403, isolate Ps-KT-0-1 & 99 \\
\hline & epiphytic, Wulai, Sansia & Tulasnella calospora & $\ldots$ \\
\hline \multirow[t]{2}{*}{ Sno6-1/JX514393 } & Cymbidium ensifolium & AJ313437, Sp1a & 99 \\
\hline & Terrestrial, Wulai, Sansia & Epulorhiza sp. & $\ldots$ \\
\hline
\end{tabular}

\footnotetext{
${ }^{\mathrm{z}}$ Ribosomal DNA-internal transcribed spacer sequences were obtained from GenBank and the reference sequence with highest blast hit was selected based on
} a known anastomosis group (AG). 
plants after colonization with a hypovirulent isolate and challenge inoculation with a virulent isolate, $\mathrm{B}$ is the percentage of surviving plants after inoculation with only a virulent isolate, and $\mathrm{C}$ is the percentage of surviving noninoculated plants. Experiments for determining plant protection of Chinese mustard grown in soil were performed according to a completely randomized design and repeated twice. Disease severity in 26-day-old Chinese mustard was assessed at the hypocotyl according to a four-point scale (Supplementary Figure S1), in which $0=$ no lesions on the hypocotyl; 1 = minor discoloration of the hypocotyl; 2 = discoloration and large, dark brown necrotic lesions on the hypocotyl, and no wire stem symptoms; and $3=$ wire stem on the hypocotyl.

Phylogenetic analysis. DNA was extracted using the DNeasy Plant mini kit (Qiagen, Hilden, Germany) according to the manufacturer's instructions. The total DNA was recovered in $50 \mu$ l of distilled deionized water and maintained at $-80^{\circ} \mathrm{C}$. The sequence of rDNAITS was amplified using forward primer ITS1 and reverse primer ITS4 (51). A polymerase chain reaction (PCR) was conducted in a GeneAmp PCR System 2700 (Applied Biosystems, Foster City, CA) by using the following thermo profile: initial denaturation at $94^{\circ} \mathrm{C}$ for $2 \mathrm{~min}$; followed by 30 cycles of denaturation at $94^{\circ} \mathrm{C}$ for $40 \mathrm{~s}$, annealing at $55^{\circ} \mathrm{C}$ for $60 \mathrm{~s}$, and extension at $72^{\circ} \mathrm{C}$ for $60 \mathrm{~s}$; and final extension at $72^{\circ} \mathrm{C}$ for $5 \mathrm{~min}$. The PCR products were purified using the MinElute PCR Purification Kit (Qiagen). Clean samples were eluted with $50 \mu \mathrm{l}$ of sterile water and quantified to conduct sequencing reactions. Cycle sequencing was conducted using BigDye version 3.1 chemistry, and sequencing was performed using an $\mathrm{ABI}$ 3100 Genetic Analyzer (Applied Biosystems). Both strands of DNA were sequenced. The sequences obtained in this study are available from GenBank under accession numbers listed in Table 1.

The rDNA-ITS sequences underwent a batch BLAST search (1) on the National Center for Biotechnology Information website (http://blast.ncbi.nlm.nih.gov/Blast.cgi). Results that were highly similar were downloaded and added to the dataset. A multiple sequence alignment of each ITS sequence was generated using Clustal W for multiple alignment (45), packaged by the BioEdit Sequence Alignment Editor (17). Phylogenetic trees were obtained from the sequences analyzed by using Molecular Evolutionary Genetics Analysis software version 5.0 (44) with a neighbor-joining method involving the Kimura two-parameter distance algorithm. In total, 1,000 bootstrap replicates were performed to estimate the node reliability of the phylogenetic trees. Bootstrap support values $>70 \%$ were considered significant. Branches that exhibited low bootstrap support values $(<70 \%)$ were removed.

Statistical analysis. All analyses were conducted using SAS 9.4 (SAS Institute, Inc., Cary, NC). The ordinal data of a rating scale were calculated by applying a nonparametric methodology (34). The rank
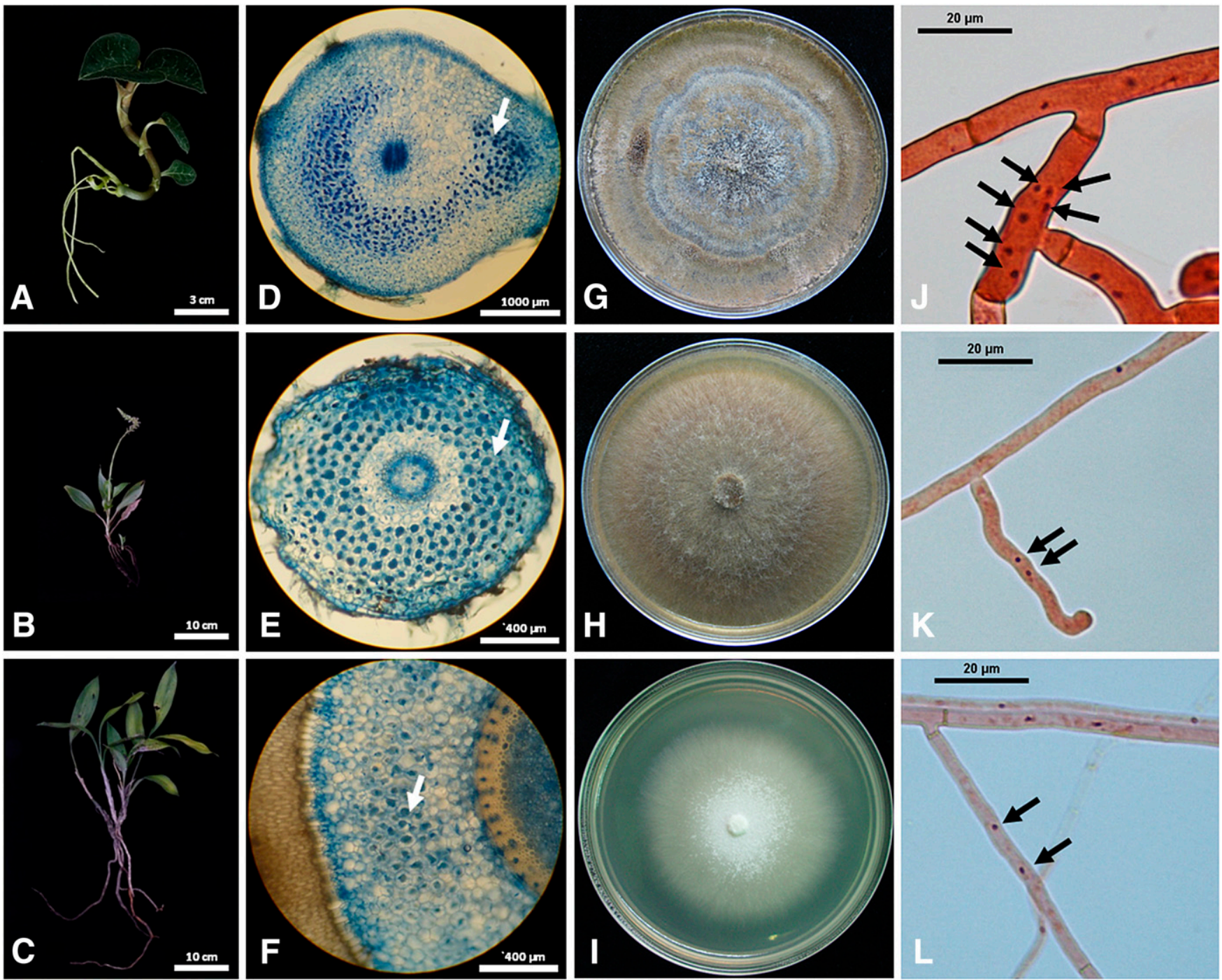

Fig. 1. Endomycorrhizal Rhizoctonia isolated from fungal pelotons in cortical cells of roots or rhizomes in wild orchid A, Anoectochilus formosanus; B, Goodyera procera; and C, Cymbidium lancifolium. D to F, Fungal pelotons (white arrows). G, to I, Cultural types of endomycorrhizal Rhizoctonia isolates. J to $\mathbf{L}$, Multinucleate and binucleate Rhizoctonia isolates are identified by the genus concept of Rhizoctonia and the number of nuclei per cell in young vegetative hyphae (black arrows). Scale bar represents $3 \mathrm{~cm}(\mathrm{~A}), 10 \mathrm{~cm}(\mathrm{~B}$ and $\mathrm{C}), 1,000 \mu \mathrm{m}(\mathrm{D}), 400 \mu \mathrm{m}$ (E and F) and $20 \mu \mathrm{m}(\mathrm{J}$ to $\mathrm{L})$. 
assigned to each observation was determined through the PROC RANK and PROC MIXED procedure used to compute test statistics and levels of significance. Estimated relative treatment effects for disease severity were calculated using $\widehat{\mathbf{p}}_{i}=1 / N\left(\overline{\mathbf{R}}_{i}-1 / 2\right)$, in which values are between 0 and 1 , where $i$ is the treatment, $N$ is the number of observations, and $\overline{\mathbf{R}}$ is the mean rank. In addition, $95 \%$ confidence interval (CI) was generated using LD_CI macro (5). A smaller value of $\widehat{\mathbf{p}}_{\boldsymbol{i}}$ indicates a lower value of disease severity after a treatment. Values of $\widehat{\mathbf{p}}_{\boldsymbol{i}}$ for two treatments differed significantly when the CI for each $\widehat{\mathbf{p}}_{\boldsymbol{i}}$ did not overlap. Data on plant protection were analyzed using a one-way analysis of variance. Mean separation was assessed using a protected posthoc Tukey's test $(P=0.05)$ after significant results from an $F$ test in SAS 9.4 were determined.

\section{Results}

Phylogenetic analysis. Isolates of endomycorrhizal Rhizoctonia sampled from fungal pelotons in orchid (Fig. 1) located at six localities in Taiwan were identified (Table 1). Selected isolates were further identified as BNR and MNR according to the number of nuclei per cell in the young vegetative hyphae (Fig. $1 \mathrm{~J}$ to L). One representative isolate from each orchid was further analyzed. In all, 3 isolates of MNR and 10 isolates of BNR were obtained in this study and assigned to multinucleate $R$. solani (teleomorph $=T$. cucumeris),
BNR (teleomorph $=$ Ceratobasidium), and binucleate $R$. repens (teleomorph $=$ Tulasnella calospora) according to the BLAST results (Table 1).

Phylogenetic analysis was conducted to group the isolates into three large clades (Fig. 2), labeled Thanatephorus (MNR), Ceratobasidium (BNR), and Tulasnella (BNR). The first two clades were categorized into different AGs. Isolates in clade Thanatephorus (MNR) formed an AG-6 clade exhibiting $88 \%$ bootstrap support and included reference sequences of $R$. solani AG-6 (mycorrhizal association, Japan; AF153780, AF153787, and AF153790) (37) and AG-6 GV (soil, Japan, AF354104) (15). Three isolates of putative AG-6 (ANOF0, ANOF4, and ANOFD1) were paired with a known representative tester strain of $R$. solani AG-6 GV (isolate NKN-2-1, Japan, provided by Ogoshi) and exhibited $\mathrm{C} 2$ reactions with the tester.

In clade Ceratobasidium (BNR), five subclades were classified according to isolates of AG-A (99\% bootstrap support), AG-B (98\% bootstrap support), AG-G (85\% bootstrap support), AG-P (77\% bootstrap support), and AG-R (100\% bootstrap support). Isolates of AG-P and AG-U were grouped into the same subclade, because anastomosis was confirmed between certain isolates of AG-P and AG-U (36). Each isolate of a putative AG was paired with a known representative tester strain of AG-A (isolate AH-1), AG-G (isolate AH-9), and AG-P (isolate C-578) (Japan, provided by Ogoshi).

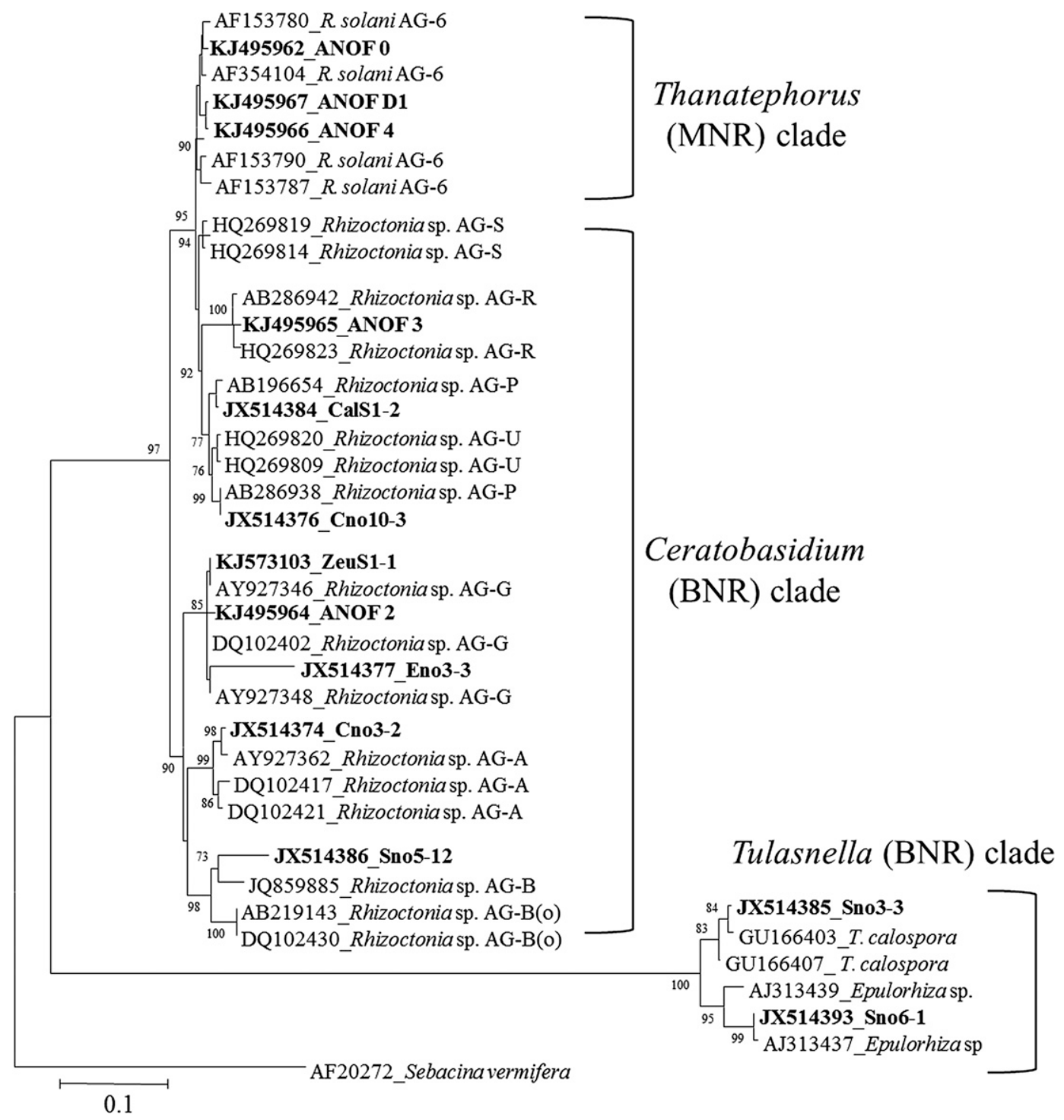

Fig. 2. Phylogeny of endomycorrhizal Rhizoctonia isolates from orchid and related fungi based on ribosomal DNA-internal transcribed spacer (ITS) sequences using the neighborjoining method. One ITS sequence from Sebacina vermifera (AF20272) was defined as an outgroup. Numbers at the nodes show bootstrap values (1,000 replicates; only values above $70 \%$ are shown) from the corresponding neighbor-joining tree. MNR = multinucleate Rhizoctonia spp. and BNR = binucleate Rhizoctonia spp. 
All isolates obtained from the orchid plants exhibited $\mathrm{C} 2$ reactions with their tester isolates. According to the high similarity of rDNA-ITS sequences and the phylogenetic analysis $(36,37)$, isolates ANOF3 and Sno5-12 were recognized as AG-R and AG-B, respectively. ANOF3 was highly homologous with Rhizoctonia AG-R isolates in GenBank (accession numbers HQ269823 and AB286942), having 98 and $99 \%$ identities $(11,36)$. Sno5-12 was grouped with Rhizoctonia AG-B (accession number JQ859885), with 93\% identity (14), forming a cluster with $A G-B_{(O)}$ (accession numbers AB219143 and DQ102430) and supported by a $98 \%$ bootstrap value.

The Tulasnella (BNR) clade, which exhibited 100\% bootstrap support, included reference sequences of T. calospora (from orchid, Thailand, GU166403; GU166407) (28) and Epulorhiza spp. (from orchid, Singapore, AJ313439; AJ313437) (23). Isolate Sno3-3 from the orchid Liparis nakaharai shared a 99\% sequence identity with T. calospora (GU166403, teleomorphic R. repens), and isolate Sno6-1 from the orchid Cymbidium ensifolium shared a 98\% sequence identity with Epulorhiza sp. (AJ313437) (99\% bootstrap support).

Virulence determination in vitro. All isolates sampled from orchid, except for isolate ANOF3 (AG-R), were mildly virulent to the 10-day-old radish, cucumber, and Chinese mustard, ranging in relative treatment effects $\left(\widehat{\mathbf{p}}_{i}\right)$ according to disease severity from 0.1 to 0.61 in radish (noninoculated control, $\widehat{\mathbf{p}}_{i}=0.1$ ), 0.28 to 0.54 in cucumber (noninoculated control, $\widehat{\mathbf{p}}_{i}=0.28$ ), and 0.18 to 0.65 in Chinese mustard (noninoculated control, $\widehat{\mathbf{p}}_{i}=0.18$ ); however, isolate ANOF3 was highly virulent to the test plants (particularly to cucumber; $\widehat{\mathbf{p}}_{\boldsymbol{i}}=0.89$ ) (Table 2). Among the isolates of endomycorrhizal Rhizoctonia, both Sno3-1 and Sno6-1 did not cause the test plants to become diseased. Nevertheless, both pathogenic $R$. solani AG-4 isolate Cabl2 and Chcab4 were highly virulent to radish, cucumber, and Chinese mustard, killing almost all test plants that exhibited wilted cotyledons and collapsed hypocotyl $\left(\widehat{\mathbf{p}}_{i}=0.88\right.$ to $0.96)$. In this study, mild symptoms were rated as $<2$ according to a 0 -to-4 scale.

Plant protection evaluation. The relative disease severity from hypovirulent isolates and from hypovirulent isolates challenged by virulent isolates on Chinese mustard, as well as the percentage of plant protection provided by the hypovirulent isolate, are shown in
Table 3. Almost all plants died when inoculated with $R$. solani AG-4 isolate Cabl2 ( $\left.\widehat{\mathbf{p}}_{i}=0.96\right)$, suggesting that Cabl2 expressed stable virulence to Chinese mustard grown in soil compared with the pathogenic isolate Chcab4 $\left(\widehat{\mathbf{p}}_{i}=0.85\right)$. Most isolates of endomycorrhizal Rhizoctonia, except for two isolates of Tulasnella (Sno6-1 and Sno3-3) and one isolate of Ceratobasidium (Sno5-12), protected Chinese mustard against $R$. solani AG-4 isolate Cabl2 (Table 3). $R$. solani AG-6 isolates (ANOF0, ANOF4, and ANOFD1) reduced disease severity and afforded moderate plant protection (45.8 to 52.4\%). Regarding endomycorrhizal BNR (Ceratobasidium) treatments, all isolates except for Sno5-12 significantly reduced the relative treatment effects $\left(\widehat{\mathbf{p}}_{i}=0.14\right.$ to 0.57 ), yielding various levels of plant protection (41.1 to 100\%). The Ceratobasidium AG-P isolates CalS1-2 and Cno10-3 provided the highest protection of 91 and $100 \%$ with the lowest relative treatment effect $\left(\widehat{\mathbf{p}}_{i}=0.14\right.$ and 0.20$)$, respectively, against $R$. solani AG-4 (Cabl2).

\section{Discussion}

Identifying the anamorphic form of genus Rhizoctonia in species-level taxonomy is difficult because the teleomorph of $R h i$ zoctonia is rarely induced under laboratory conditions (37). The diversity of endomycorrhizal Rhizoctonia isolates from orchid reflects various AGs. Moreover, isolates of $R$. solani AG-6 form a close relationship with BNR (AG-P, AG-R, AG-S, and AG-U). R. solani AG-6 and AG-12 have been reported to exhibit mycorrhizal associations with wild orchid (10,31). Phylogenetic analysis of rDNA-ITS sequences has shown that some BNR are paraphyletic with MNR $(15,24,48)$. In the present study, we found that BNR isolates were clarified as mycorrhizal fungi associating with orchid. Although these AGs contain pathogenic isolates (40), certain isolates have been reported to be hypovirulent or nonpathogenic isolates that protect plant hosts against pathogens $(19,20,22,39)$.

Several researchers have suggested that virulence determination should involve evaluating diseases according to a continuum between highest and lowest virulence (39) and have recommended using suitable hosts for identifying hypovirulent Rhizoctonia isolates that could control pathogens $(19,20)$. Juan-Abgona et al. (20) indicated that cucumber cultivars were more susceptible than radish cultivars when tested in vitro against isolates of Rhizoctonia, and

Table 2. Relative ranking of disease severities on 10-day-old seedlings of radish, cucumber, and Chinese mustard that were inoculated with individual isolates of endomycorrhizal and pathogenic Rhizoctonia spp ${ }^{\mathrm{y}}$

\begin{tabular}{|c|c|c|c|c|c|c|c|}
\hline \multirow[b]{2}{*}{ Isolate } & \multirow[b]{2}{*}{$\mathbf{A G}^{\mathbf{z}}$} & \multicolumn{2}{|c|}{ Radish } & \multicolumn{2}{|c|}{ Cucumber } & \multicolumn{2}{|c|}{ Chinese mustard } \\
\hline & & $\widehat{\mathbf{p}}_{i}$ & CI for $\widehat{\mathbf{p}}_{i}$ & $\widehat{\mathbf{p}}_{i}$ & CI for $\widehat{\mathbf{p}}_{i}$ & $\widehat{\mathbf{p}}_{i}$ & CI for $\widehat{\mathbf{p}}_{i}$ \\
\hline \multicolumn{8}{|c|}{ Thanatephorus } \\
\hline Cabl2 & 4 & 0.88 & $0.86-0.90$ & 0.91 & $0.90-0.92$ & 0.93 & $0.92-0.93$ \\
\hline Chcab4 & 4 & 0.96 & $0.95-0.96$ & 0.92 & $0.91-0.92$ & 0.93 & $0.92-0.93$ \\
\hline ANOF0 & 6 & 0.40 & $0.35-0.46$ & 0.38 & $0.32-0.45$ & 0.43 & $0.36-0.48$ \\
\hline ANOF4 & 6 & 0.61 & $0.54-0.67$ & 0.41 & $0.34-0.49$ & 0.63 & $0.58-0.69$ \\
\hline ANOFD1 & 6 & 0.56 & $0.49-0.62$ & 0.35 & $0.29-0.41$ & 0.65 & $0.61-0.70$ \\
\hline \multicolumn{8}{|c|}{ Ceratobasidium } \\
\hline Cno3-2 & A & 0.55 & $0.49-0.60$ & 0.51 & $0.44-0.59$ & 0.34 & $0.28-0.41$ \\
\hline Sno5-12 & $\mathrm{B}$ & 0.47 & $0.43-0.51$ & 0.32 & $0.27-0.36$ & 0.38 & $0.32-0.47$ \\
\hline Eno3-3 & $\mathrm{G}$ & 0.51 & $0.46-0.56$ & 0.40 & $0.33-0.47$ & 0.61 & $0.55-0.66$ \\
\hline ZeuS1-1 & G & 0.48 & $0.44-0.52$ & 0.54 & $0.47-0.62$ & 0.61 & $0.53-0.68$ \\
\hline ANOF2 & G & 0.50 & $0.45-0.54$ & 0.50 & $0.42-0.57$ & 0.35 & $0.28-0.44$ \\
\hline Cno10-3 & $\mathrm{P}$ & 0.48 & $0.44-0.52$ & 0.48 & $0.40-0.56$ & 0.41 & $0.35-0.47$ \\
\hline CalS1-2 & $\mathrm{P}$ & 0.55 & $0.49-0.60$ & 0.54 & $0.47-0.62$ & 0.39 & $0.33-0.46$ \\
\hline ANOF3 & $\mathrm{R}$ & 0.77 & $0.71-0.82$ & 0.89 & $0.88-0.90$ & 0.82 & $0.77-0.85$ \\
\hline \multicolumn{8}{|l|}{ Tulasnella } \\
\hline Sno3-3 & $\ldots$ & 0.10 & $0.09-0.11$ & 0.28 & $0.27-0.30$ & 0.18 & $0.16-0.19$ \\
\hline Sno6-1 & $\ldots$ & 0.10 & $0.09-0.11$ & 0.28 & $0.27-0.30$ & 0.18 & $0.16-0.19$ \\
\hline Control & $\ldots$ & 0.10 & $0.09-0.11$ & 0.28 & $0.27-0.30$ & 0.18 & $0.16-0.19$ \\
\hline
\end{tabular}


isolates identified as hypovirulent should consistently exhibit a hypovirulent reaction on other crops when tested in vitro and in soil. In this study, endomycorrhizal Rhizoctonia isolates caused slight discoloration at the basal site of the hypocotyl and a low disease severity in 10-day-old radish, cucumber, and Chinese mustard under an in vitro conditions. An exception was the ANOF3 isolate (AG-R), which was more virulent to tested plants. The results revealed that almost all of the endomycorrhizal Rhizoctonia spp. isolated from wild orchid exerted low virulence on test plants. However, certain AGs of genera Thanatephorus and Ceratobasidium are pathogenic on a range of hosts. Thus, the virulence of endomycorrhizal Rhizoctonia isolates should be evaluated using several plants in further research.

Previous studies have revealed that $R$. solani AG-4 is an economically vital soilborne plant pathogen that affects various hosts $(2,46)$. In the present study, the damping-off of Chinese mustard was significantly reduced when seedlings grown in soil were protected before a challenge inoculation with $R$. solani AG 4 . However, the percentages of plant protection caused by isolates of endomycorrhizal Rhizoctonia varied. Rhizoctonia fungi may exhibit similar characteristics, such as types of disease symptoms caused or host preferences within the same AG (21). The ability of endomycorrhizal Rhizoctonia spp. to stimulate the germination and growth of orchid seed has been predicted according to phylogenetic relationships (29). Therefore, we expected that closely related isolates or AGs might be similar in plant-protective ability. According to AG determination, certain isolates of BNR from soil have been used in greenhouse or field trials to ameliorate damping-off

Table 3. Relative ranking of disease severities on 26-day-old Chinese mustard grown in soil inoculated with individual isolates of endomycorrhizal and pathogenic Rhizoctonia spp. and inoculated with putatively protective isolates on 10-day-old plants than challenged with pathogenic Rhizoctonia isolates 6 days later

\begin{tabular}{|c|c|c|c|c|c|c|}
\hline \multirow[b]{2}{*}{ Isolate } & \multirow[b]{2}{*}{$\mathbf{A G}^{\mathbf{y}}$} & \multicolumn{2}{|c|}{$\begin{array}{l}\text { Inoculating with } \\
\text { each isolate }\end{array}$} & \multicolumn{3}{|c|}{$\begin{array}{c}\text { Challenging with } \\
\text { pathogenic Cabl2 after } \\
\text { inoculating putatively } \\
\text { protective isolate }\end{array}$} \\
\hline & & $\widehat{\mathbf{p}}_{i}$ & CI for $\widehat{\mathbf{p}}_{i}$ & $\widehat{\mathbf{p}}_{i}$ & CI for $\widehat{\mathbf{p}}_{i}$ & $\mathbf{P P}(\%)^{2}$ \\
\hline \multicolumn{7}{|c|}{ Thanatephorus } \\
\hline Cabl2 & 4 & 0.96 & $0.95-0.96$ & $\ldots$ & $\ldots$ & $\ldots$ \\
\hline Chcab4 & 4 & 0.85 & $0.77-0.90$ & $\ldots$ & $\ldots$ & $\ldots$ \\
\hline ANOF0 & 6 & 0.46 & $0.41-0.51$ & 0.50 & $0.40-0.61$ & $45.8 \mathrm{~cd}$ \\
\hline ANOF4 & 6 & 0.42 & $0.41-0.43$ & 0.48 & $0.38-0.57$ & $48.7 \mathrm{~cd}$ \\
\hline ANOFD1 & 6 & 0.42 & $0.41-0.43$ & 0.49 & $0.40-0.59$ & $52.4 \mathrm{~cd}$ \\
\hline \multicolumn{7}{|c|}{ Ceratobasidium } \\
\hline Cno3-2 & A & 0.42 & $0.41-0.43$ & 0.51 & $0.40-0.62$ & $41.1 \mathrm{de}$ \\
\hline Sno5-12 & $\mathrm{B}$ & 0.44 & $0.40-0.47$ & 0.65 & $0.56-0.72$ & 17.9 ef \\
\hline Eno3-3 & G & 0.52 & $0.45-0.59$ & 0.48 & $0.38-0.58$ & $54.8 \mathrm{~cd}$ \\
\hline ZeuS1-1 & G & 0.44 & $0.40-0.47$ & 0.39 & $0.30-0.49$ & $75.4 \mathrm{bc}$ \\
\hline ANOF2 & G & 0.42 & $0.41-0.43$ & 0.57 & $0.50-0.64$ & $44.6 \mathrm{de}$ \\
\hline Cno10-3 & $\mathrm{P}$ & 0.46 & $0.41-0.51$ & 0.20 & $0.14-0.29$ & $91.1 \mathrm{ab}$ \\
\hline CalS1-2 & $P$ & 0.42 & $0.41-0.43$ & 0.14 & $0.11-0.18$ & $100 \mathrm{a}$ \\
\hline ANOF3 & $\mathrm{R}$ & 0.51 & $0.44-0.58$ & 0.44 & $0.35-0.53$ & $60.7 \mathrm{~cd}$ \\
\hline \multicolumn{7}{|l|}{ Tulasnella } \\
\hline Sno3-3 & & 0.42 & $0.41-0.43$ & 0.71 & $0.65-0.75$ & $4.8 \mathrm{f}$ \\
\hline Sno6-1 & $\ldots$ & 0.42 & $0.41-0.43$ & 0.71 & $0.65-0.75$ & $8.9 \mathrm{f}$ \\
\hline Control & $\ldots$ & 0.42 & $0.41-0.43$ & 0.73 & $0.69-0.77$ & $0 \mathrm{f}$ \\
\hline
\end{tabular}

$\mathrm{x}$ Disease severity was originally rated on a 0 to 3 scale and the single variable ranked using the PROC RANK procedure. A relative disease severity $\left[\widehat{\mathrm{p}}_{i}=\right.$ $\left.1 / \mathrm{N}\left(\overline{\mathrm{R}}_{i}-1 / 2\right)\right]$ was calculated using a mean rank formula $\left(\overline{\mathrm{R}}_{i}=1 / \mathrm{n}_{\mathrm{i}}\right.$ $\left.\sum_{k=1}^{n i} R_{\mathrm{ik}}\right)$ and confidence intervals (CI) generated using the LD_CI macro. Values of $\widehat{p}_{i}$ between two accessions are significantly different from each other if $95 \%$ CI for each $\widehat{p}_{i}$ does not overlap.

y Anastomosis group.

${ }^{\mathrm{z}}$ Percent plant protection $(\mathrm{PP})$ was calculated using the formula Protection $(\%)=$ $[(\mathrm{A}-\mathrm{B}) /(\mathrm{C}-\mathrm{B})] \times 100$, where $\mathrm{A}=$ the percentage of surviving plants after colonization with a hypovirulent isolate and challenge inoculation with a virulent isolate, $\mathrm{B}=$ the percentage of surviving plants after inoculation with only a virulent isolate, and $\mathrm{C}=$ the percentage of surviving noninoculated plants. Values followed by the same letter were not significantly different according to post hoc Tukey's test $(P=0.05)$ by using one-way analysis of variance procedure. in various crops, such as bean (e.g., AG-G and AG-R) $(18,39,50)$, cucumber (e.g., AG-G, AG-P, and AG-B $(0)$ ) $(20,39)$, and cotton (e.g., AG-G and AG-R) (19). We found that endomycorrhizal Rhizoctonia isolates are related to the aforementioned hypovirulent BNR isolates of AGs. Although certain Rhizoctonia spp. are plant pathogens, the nutrient requirements of endomycorrhizal Rhizoctonia spp. remain unknown $(25,48)$.

In experiments conducted using plug trays, isolates from the terrestrial orchid species Cheirostylis hungyehensis (Cno10-3) and Calanthe sylvatica (CalS1-2) yielded the most effective plant protection. Both isolates belonged to AG-P and exhibited mild relative treatment effects on the disease severity in 10-day-old test plants and high levels of plant protection with mild relative treatment effects in 26-dayold Chinese mustard grown in soil. Certain isolates of hypovirulent Rhizoctonia exhibit abilities to protect seedlings against pathogenic Rhizoctonia isolates through competition of nutrients (9) and colonization of infection sites (42), for example. Plant protection is sometimes effective when the control agent is related to the pathogen because their requirements are likely similar (43). The evaluated isolates of AG-6 and AG-P produced abundant mycelium and rapidly colonized on the hypocotyl of the seedlings, as did the pathogen $R$. solani AG 4. Extensive colonization is typically considered a favorable sign when attempting to control pathogens (39). Sneh and IchielevichAuster (41) demonstrated that isolates in AG-B $\mathrm{B}_{(\mathrm{O})}$ and AG-P induce plant resistance and protected cucumber seedlings. Furthermore, phenylalanine ammonia lyase, peroxidase, the pathogenesis-related (PR)-2 family of proteins, chitinase (PR-3 family), salicylic acid, pectic substances, and suberin have been involved in resistance responses $(7,18)$. In the present study, plants colonized by AG-P isolates accumulated pectic substances and phenolic compounds in the hypocotyl that were not apparent in noninoculated controls. The isolates of AG-P exhibited the strong ability to colonize the base regions of seedlings, producing loose and small infection cushions that may not be effective in penetration and colonization (unpublished). Recently, colonizing Arabidopsis thaliana with hypovirulent BNR isolates of AG-A and $A G-B_{(O)}$ induced genes involved in the systemic acquired resistance, induced systemic resistance, and phytoalexin production pathways (35). Plant protection provided by isolates of AG-P sampled from orchid may involve fungal competition regarding space and nutrition and induce innate immune system responses in plants. The combination of high protection levels and a low tendency for disease severity suggests that isolates of AG-P are the most promising candidates for controlling Rhizoctonia damping-off in Chinese mustard. Although certain isolates of AG-P were recognized as plant pathogens, some isolates were considered hypovirulent BNR that could control damping-off (39). Applying AG-P to host plants, as previously reported, requires further investigation. A recent study by Veldre et al. (48) indicated that Rhizoctonia fungi isolated from soil and symbiont generally exhibited a low ability to cause plant disease compared with pathogenic Rhizoctonia fungi isolated from the host.

The isolates of endomycorrhizal Rhizoctonia described in this study were obtained from the fungal pelotons in the cortical cells of orchid roots or rhizomes, suggesting that the fungi had functional mycorrhizal associations with orchid plants. Our findings revealed that hypovirulent isolates of Rhizoctonia can be identified in orchid. Moreover, isolates of endomycorrhizal Rhizoctonia may be effective in controlling the Rhizoctonia damping-off of Chinese mustard grown in soil and yield low levels of virulence in radish, cucumber, and Chinese mustard under in vitro conditions. Such isolates may be applicable for treating vegetable crops. Thus, we can justify that two endomycorrhizal isolates of AG-P are useful for biological control. However, understanding the mode of plant protection provided by isolates of AG-P is necessary for developing efficient procedures and preparations and for improving the efficacy of application practices.

\section{Acknowledgments}

We thank Y. I. Lee (Botany Department, National Museum of Natural Science, Taichung, Taiwan) and J. F. Xu (National Chung Hsing University, Taichung, Taiwan) for providing the native orchid plants used in this study. 


\section{Literature Cited}

1. Altschul, S. F., Madden, T. L., Schäffer, A. A., Zhang, J. H., Zhang, Z., Miller, W., and Lipman, D. J. 1997. Gapped BLAST and PSI-BLAST: A new generation of protein database search programs. Nucleic Acids Res. 25: 3389-3402.

2. Anderson, N. A. 1982. The genetics and pathology of Rhizoctonia solani. Annu. Rev. Phytopathol. 20:329-347.

3. Arditti, J. 1992. Fundamentals of Orchid Biology. John Wiley \& Sons, New York.

4. Bandoni, R. 1979. Safranin O as a rapid nuclear stain for fungi. Mycologia 71: 873-874

5. Brunner, E., Domhof, S., and Langer, F. 2002. Nonparametric Analysis of Longitudinal Data in Factorial Experiments. John Wiley \& Sons, New York.

6. Burpee, L., Sanders, P., Cole, H., and Kim, S. 1978. A staining technique for nuclei of Rhizoctonia solani and related fungi. Mycologia 70:1281-1283.

7. Cardinale, F., Ferraris, L., Valentino, D., and Tamietti, G. 2006. Induction of systemic resistance by a hypovirulent Rhizoctonia solani isolate in tomato. Physiol. Mol. Plant Pathol. 69:160-171.

8. Carling, D. E. 1996. Grouping in Rhizoctonia solani by hyphal anastomosis reaction. Pages 37-47 in: Rhizoctonia Species: Taxonomy, Molecular Biology, Ecology, Pathology and Disease Control. B. Sneh, S. Jabajihare, S. Neate, and G. Dijst, eds. Kluwer Academic Publisher, Dordrecht, The Netherlands.

9. Carling, D. E., Baird, R. E., Gitaitis, R. D., Brainard, K. A., and Kuninaga, S. 2002. Characterization of AG-13, a newly reported anastomosis group of Rhizoctonia solani. Phytopathology 92:893-899.

10. Carling, D. E., Pope, E. J., Brainard, K. A., and Carter, D. A. 1999. Characterization of mycorrhizal isolates of Rhizoctonia solani from an orchid, including AG-12, a new anastomosis group. Phytopathology 89:942-946.

11. Copes, W. E., Rodriguez-Carres, M., Toda, T., Rinehart, T. A., and Cubeta, M. A. 2011. Seasonal prevalence of species of binucleate Rhizoctonia fungi in growing medium, leaf litter, and stems of container-grown Azalea. Plant Dis. 95:705-711.

12. Cribb, P. J., Kell, S. P., Dixon, K. W., and Barrett, R. L. 2003. Orchid conservation: A global perspective. Pages 1-24 in: Orchid conservation. K. W. Dixon, S. P. Kell, and P. J. Cribbs, eds. Natural History Publications, Kota Kinabalu, Malaysia.

13. Dearnaley, J. D. 2007. Further advances in orchid mycorrhizal research. Mycorrhiza 17:475-486.

14. Fang, X. L., Finnegan, P. M., and Barbetti, M. J. 2013. Wide variation in virulence and genetic diversity of binucleate Rhizoctonia isolates associated with root rot of strawberry in Western Australia. PLoS One 8:E55877.

15. Gonzalez, D., Carling, D. E., Kuninaga, S., Vilgalys, R., and Cubeta, M. A. 2001. Ribosomal DNA systematics of Ceratobasidium and Thanatephorus with Rhizoctonia anamorphs. Mycologia 93:1138-1150.

16. González García, V., Onco, P., and Rubio Susan, V. 2006. Review. Biology and Systematics of the form genus Rhizoctonia. Span. J. Agric. Res. 4:55-79.

17. Hall, T. A. 1999. Bioedit: A user-friendly biological sequence alignment editor and analysis program for Windows 95/98/NT. Nucleic Acids Symp. Ser. 41:95-98.

18. Jabaji-Hare, S., Chamberland, H., and Charest, P. M. 1999. Cell wall alterations in hypocotyls of bean seedlings protected from Rhizoctonia stem canker by a binucleate Rhizoctonia isolate. Mycol. Res. 103:1035-1043.

19. Jabaji-Hare, S., and Neate, S. M. 2005. Nonpathogenic binucleate Rhizoctonia spp. and benzothiadiazole protect cotton seedlings against Rhizoctonia damping-off and Alternaria leaf spot in cotton. Phytopathology 95:1030-1036.

20. Juan-Abgona, R. V., Katsuno, N., Kageyama, K., and Hyakumachi, M. 1996. Isolation and identification of hypovirulent Rhizoctonia spp. from soil. Plant Pathol. 45:896-904.

21. Keijer, J., Korsman, M. G., Dullemans, A. M., Houterman, P. M., de Bree, J., and Van Silfhout, C. H. 1997. In vitro analysis of host plant specificity in Rhizoctonia solani. Plant Pathol. 46:659-669.

22. Khan, F. U., Nelson, B. D., and Helms, T. C. 2005. Greenhouse evaluation of binucleate Rhizoctonia for control of $R$. solani in soybean. Plant Dis. 89:373-379.

23. Ma, M., Tan, T. K., and Wong, S. M. 2003. Identification and molecular phylogeny of Epulorhiza isolates from tropical orchids. Mycol. Res. 107:1041-1049.

24. Moncalvo, J. M., Nilsson, R. H., Koster, B., Dunham, S. M., Bernauer, T., Matheny, P. B., Porter, T. M., Margaritescu, S., Weiß, M., and Garnica, S. 2006. The cantharelloid clade: Dealing with incongruent gene trees and phylogenetic reconstruction methods. Mycologia 98:937-948.

25. Mosquera-Espinosa, A. T., Bayman, P., Prado, G. A., Gomez-Carabali, A., and Otero, J. T. 2013. The double life of Ceratobasidium: Orchid mycorrhizal fungi and their potential for biocontrol of Rhizoctonia solani sheath blight of rice. Mycologia 105:141-150.

26. Muslim, A., Horinouchi, H., and Hyakumachi, M. 2003. Control of Fusarium crown and root rot of tomato with hypovirulent binucleate Rhizoctonia in soil and rock wool systems. Plant Dis. 87:739-747.

27. Muslim, A., Horinouchi, H., and Hyakumachi, M. 2003. Suppression of Fusarium wilt of spinach with hypovirulent binucleate Rhizoctonia. J. Gen. Plant Pathol. 69:143-150.
28. Nontachaiyapoom, S., Sasirat, S., and Manoch, L. 2010. Isolation and identification of Rhizoctonia-like fungi from roots of three orchid genera, Paphiopedilum, Dendrobium, and Cymbidium, collected in Chiang Rai and Chiang Mai provinces of Thailand. Mycorrhiza 20:459-471.

29. Otero, J. T., Bayman, P., and Ackerman, J. D. 2005. Variation in mycorrhizal performance in the epiphytic orchid Tolumnia variegata in vitro: The potential for natural selection. Evol. Ecol. 19:29-43.

30. Pascual, C. B., Raymundo, A. D., and Hyakumachi, M. 2000. Efficacy of hypovirulent binucleate Rhizoctonia sp. to control banded leaf and sheath blight in corn. J. Gen. Plant Pathol. 66:95-102.

31. Pope, E. J., and Carter, D. A. 2001. Phylogenetic placement and host specificity of mycorrhizal isolates belonging to AG-6 and AG-12 in the Rhizoctonia solani species complex. Mycologia 93:712-719.

32. Poromarto, S. H., Nelson, B. D., and Freeman, T. P. 1998. Association of binucleate Rhizoctonia with soybean and mechanism of biocontrol of Rhizoctonia solani. Phytopathology 88:1056-1067.

33. Roberts, P. 1999. Rhizoctonia-Forming Fungi: A Taxonomic Guide. Royal Botanic Gardens, Kew, UK

34. Shah, D. A., and Madden, L. V. 2004. Nonparametric analysis of ordinal data in designed factorial experiments. Phytopathology 94:33-43.

35. Sharon, M., Freeman, S., and Sneh, B. 2011. Assessment of resistance pathways induced in Arabidopsis thaliana by hypovirulent Rhizoctonia spp. isolates. Phytopathology 101:828-838.

36. Sharon, M., Kuninaga, S., Hyakumachi, M., Naito, S., and Sneh, B. 2008 Classification of Rhizoctonia spp. using rDNA-ITS sequence analysis supports the genetic basis of the classical anastomosis grouping. Mycoscience 49:93-114.

37. Sharon, M., Kuninaga, S., Hyakumachi, M., and Sneh, B. 2006. The advancing identification and classification of Rhizoctonia spp. using molecular and biotechnological methods compared with the classical anastomosis grouping. Mycoscience 47:299-316.

38. Smith, S. E., and Read, D. J. 2008. Mycorrhizal Symbiosis, 3rd ed. Academic Press, London.

39. Sneh, B. 1996. Non pathogenic isolates of Rhizoctonia (np-R) spp. and their role in biological control. Pages 473-483 in: Rhizoctonia Species: Taxonomy, Molecular Biology, Ecology, Pathology and Disease Control B. Sneh, S. Jabajihare, S. Neate, and G. Dijst, eds. Kluwer Academic Publisher, Dordrecht, The Netherlands.

40. Sneh, B., Burpee, L., and Ogoshi, A. 1991. Identification of Rhizoctonia Species. American Phytopathological Society, St. Paul, MN.

41. Sneh, B., and Ichielevich-Auster, M. 1998. Induced resistance of cucumber seedlings caused by some non-pathogenic Rhizoctonia (np-R) isolates. Phytoparasitica 26:27-38.

42. Sneh, B., Ichielevich-Auster, M., and Plaut, Z. 1989. Mechanism of seedling protection induced by a hypovirulent isolate of Rhizoctonia solani. Can. J. Bot. 67:2135-2141.

43. Sneh, B., Yamoah, E., and Stewart, A. 2004. Hypovirulent Rhizoctonia spp isolates from New Zealand soils protect radish seedlings against dampingoff caused by $R$. solani. N. Z. Plant Prot. 57:54-58.

44. Tamura, K., Peterson, D., Peterson, N., Stecher, G., Nei, M., and Kumar, S 2011. MEGA5: Molecular evolutionary genetics analysis using maximum likelihood, evolutionary distance, and maximum parsimony methods. Mol. Biol. Evol. 28:2731-2739.

45. Thompson, J. D., Higgins, D. G., and Gibson, T. J. 1994. ClustalW: Improving the sensitivity of progressive multiple sequence alignment through sequence weighting, positions-specific gap penalties and weight matrix choice. Nucleic Acids Res. 22:4673-4680.

46. Tu, C., Hsieh, T., and Chang, Y. 1996. Vegetable diseases incited by Rhizoctonia spp. Pages 369-377 in: Rhizoctonia Species: Taxonomy, Molecular Biology, Ecology, Pathology and Disease Control. B. Sneh, S Jabajihare, S. Neate, and G. Dijst, eds. Kluwer Academic Publisher, Dordrecht, The Netherlands.

47. Uetake, Y., Obayashi, K., Ogoshi, A., and Tsutsui, K. 1988. Identification of Rhizoctonia species isolated from orchids. Ann. Phytopathol. Soc. Jpn. 54: 114.

48. Veldre, V., Abarenkov, K., Bahram, M., Martos, F., Selosse, M. A., Tamm, H., Kõljalg, U., and Tedersoo, L. 2013. Evolution of nutritional modes of Ceratobasidiaceae (Cantharellales, Basidiomycota) as revealed from publicly available ITS sequences. Fungal Ecol. 6:256-268.

49. Warcup, J. 1981. The mycorrhizal relationships of Australian orchids. New Phytol. 87:371-381.

50. Wen, K., Seguin, P., St-Arnaud, M., and Jabaji-Hare, S. 2005. Real-time quantitative RT-PCR of defense-associated gene transcripts of Rhizoctonia solani-infected bean seedlings in response to inoculation with a nonpathogenic binucleate Rhizoctonia isolate. Phytopathology 95:345-353

51. White, T. J., Bruns, T., Lee, S., and Taylor, J. 1990. Amplification and direct sequencing of fungal ribosomal RNA genes for phylogenetics. Pages 315-322 in: PCR Protocols: A Guide to Methods and Applications. M. A Innis, D. H. Gelfand, J. J. Snunsu, and T. J. White, eds. Academic Press, San Diego, CA. 